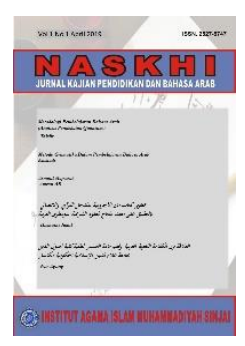

\title{
PENINGKATAN KEMAMPUAN DEBAT BAHASA ARAB MAHASISWA MELALUI METODE SUGGESTOPEDIA
}

\author{
Nur Agung \\ Institut Agama Islam Muhammadiyah Sinjai \\ comaagung@gmail.com
}

\begin{abstract}
تجريد
اليوم، قد غيرت أهداف تعليم اللغة العربية جوهريا. في الماضي هدف تعليم اللغة العربية لترقية فهم

نظرية اللغوية ولكن الآن كثير من علماء اللغة يهتمون على ترقية كفاءة الطلاب في مهارات اللغوية

واحدى منها مهارة الكلام. وفيها طرق لتمارن الطلاب عند التكلم باللغة العربية منها مناظرة العلمية.

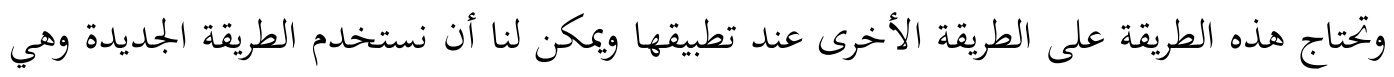

طريقة سوغستوفيديا وفيها يمكن للطلبة أن تعبر فكرتم باللغة العربية. وبحث الباحث عن ترقية كفاءة

الطلبة في مناظرة العلمية باللغة العربية باستخدام طريقة سوغسوفيديا.
\end{abstract}

\begin{abstract}
Abstrak
Dewasa ini, pembelajaran bahasa Arab telah mengalami pergeseran tujuan yang cukup signifikan. Jika beberapa dekade lalu, pembelajaran bahasa Arab berorientasi pada pemahaman teori bahasa, di era sekarang bahasa Arab lebih memprioritaskan pada penguasaan keterampilan bahasa sebagai alat komunikasi. Debat berbahasa Arab merupakan salah satu metode untuk melatih kemampuan bicara seorang penutur asing, banyak cara yang dilakukan untuk melatih kemampuan ini, salah satunya adalah dengan menerapkan Metode Suggestopedia. Metode ini memberikan kesempatan kepada penutur asing untuk berani mengungkapkan gagasannya dalam bahasa Arab karena didukung oleh kondisi yang kondusif. Penelitin ini berusaha untuk menemukan seberapa besar peningkatan kemampuan debat bahasa Arab yang didapat oleh mahasiswa setelah menggunakan Metode Suggestopedia sebagai metode pembelajarannya.
\end{abstract}




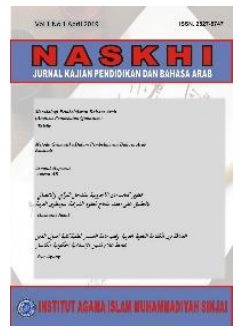

\section{A. PENDAhuluan}

Penguasaan terhadap bahasa adalah kebutuhan primer bagi setiap manusia. Semua aspek kehidupan manusia tidak akan lepas dari bahasa, ilmu pengetahuan contohnya. Dengan bahasa seseorang mencari ilmu, dengan bahasa ia menyampaikan ilmu, dan dengan bahasa ia menguasai ilmu. Dilansir dari hasil penelitian Dailatus Syamsiah, bahwa terdapat ribuan bahasa yang digunakan oleh masyarakat dunia, namun 10 di antaranya di tetapkan sebagai bahasa dengan pengguna terbanyak. Bahasa Arab menjadi bahasa ke 5 dengan pengguna terbanyak di seluruh dunia setelah Mandarin, Inggris, Hindi, dan Spanyol (Syamsiah, 2016, 52).

Ferguson, seorang linguis terkenal menyebutkan bahwa bahasa Arab adalah bahasa yang paling agung saat ini, karena posisinya sebagai bahasa Semit yang tidak mengalami banyak perubahan sejak awal mula kemunculannya hingga saat ini jika dibandingkan dengan bahasa lain (Madkur, 2002, 39). Oleh karena itu, pengajaran bahasa Arab menjadi hal yang wajib untuk dilakukan oleh lembaga pendidikan, terutama lembaga pendidikan Islam. Hal ini juga berlaku di Indonesia dengan mayoritas penduduk muslim terbanyak di dunia.

Bahasa Arab telah ditetapkan sebagai salah satu bahasa asing yang wajib dikuasai oleh mahasiswa Perguruan Tinggi Agama Islam (selanjutnya disebut PTAI), bahkan tidak sedikit PTAI yang menyusun program khusus untuk membantu mahasiswanya dalam menguasai bahasa Arab. UIN Maulana Malik Ibrahim Malang contohnya, PTAI ini mengharuskan mahasiswa tahun pertama untuk menguasai bahasa Arab dan Inggris melalui program ma'had. Dalam program ini, mahasiswa 'dipaksa' untuk menggunakan dua bahasa asing secara bergantian. Program ini bertujuan agar mahasiswa bisa menjangkau ranah internasional berbekal bahasa yang sudah mereka kuasai.

Program serupa juga dilakukan oleh PTAI lain di Indonesia, berbagai cara dilaksanakan agar mahasiswa mampu menjadikan bahasa Arab sebagai bahasa pengantar dalam berbagai kesempatan. Namun, di balik programprogram besar tersebut, stigma yang mengatakan bahwa bahasa Arab itu sulit masih tetap ada. Jamsuri Muhammad dan Mahdi Mas'ud dalam penelitiannya menemukan bahwa 30 mahasiswa ilmu politik pada International Islamic University Malaysia mengalami kesulitan belajar Bahasa Arab, dan penyebab utama dari kesulitan itu tidak terletak pada program pembelajaran yang kurang jitu, tetapi karena ketiadaan motivasi atau minat mahasiswa untuk menguasai bahasa Arab (Masnun, 2018, 175).

Motivasi dan minat mahasiswa yang rendah tersebut dipengaruhi oleh berbagai faktor, salah satu di antaranya adalah penggunaan metode pengajaran yang tidak tepat, sehingga menjadikan mahasiswa semakin kesulitan mempelajari bahasa Arab. Menurut Bartley dalam E.Sadtono (Cahyono, tth, 3) bahwa mahasiswa akan menunjukkan gejala ketidaksukaan terhadapa bahasa asing yang dipelajari, jika metode yang digunakan pengajar tidak 


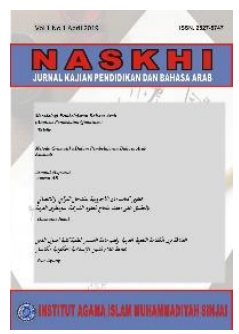

NASKHI

Jurnal Kajian Pendidikan dan Bahasa Arab

Volume 2, No. 1, 2020

ISSN (print) : 2527-5747

ISSN (online) : 2716-3369

Homepage : https://journal.iaimsinjai.ac.id/index.php/naskhi

menampakkan hasil yang signifikan pada kemampuannya. Sebab itu, dibutuhkan metode pengajaran yang bisa meningkatkan motivasi mahasiswa.

Banyak metode pengajaran bahasa asing umumnya dan bahasa Arab khususnya yang bisa digunakan untuk meningkatkan motivasi belajar mahasiswa, baik metode klasik atau modern. Salah satu metode yang bisa digunakan adalah Seggestopedia. Metode ini termasuk metode pembelajaran bahasa Arab modern yang menekankan pada aspek penguasaan bahasa sebagai alat komunikasi.

Metode Suggestopedia dikembangkan oleh seorang psikoterapis berkebangsaan Bulgaria, Georgi Lozanof pada tahun 1975. Ia meneliti tentang pengaruh aplikasi Suggestology (sebuah ilmu yang mempelajari pengaruh nonrasional terhadap perilaku manusia) terhadap penguasaan bahasa asing (Hafidah, 2012, 202). Melalui metode ini, pengajar mencoba memberikan stimulis kepada mahasiswa melalui alam bawah sadarnya bahwa mereka mampu menguasai materi yang diajarkan. Stimulus tersebut diberikan melalui penataan ruang belajar yang kondusif, penggunaan intonasi dan ritme penyampaian materi yang baik, menciptakan suasan belajar senyaman mungkin, dan sebagainya.

Penggunaan metode ini dalam pembelajaran bahasa Arab bukanlah hal baru, pada tahun 2018, Fauziya Hasan Saefullah membuktikan bahwa kemampuan berbicara siswa mengalami peningkatan setelah mengikuti pembelajaran menggunakan metode Suggestopedia (Saefullah, 2018, 59). Di samping itu, M. Khakim Maulana juga menyebutkan dalam penelitiannya, bahwa kemampuan mahasiswa dalam Maharah Kalam juga mengalami perubahan yang signifikan setelah menggunakan metode Suggestopedia, terutama peningkatan semangat mahasiswa dalam mempelajari bahasa Arab dan keberanian mereka untuk menggunakannya dalam berkomunikasi (Maulana, tth, 1).

Kemampuan mahasiswa dalam berbicara Bahasa Arab dapat diukur melalui kemampuan mereka saat berdiskusi atau berdebat dengan bahasa Arab. Fithrotul Jannah menyebutkan bahwa debat merupakan salah satu penyokong keterampilan bahasa Arab yang efektif, karena mahasiswa diharuskan untuk menguasai berbagai kosa kata, tata bahasa, serta cara penyampaian argumen dengan bahasa Arab (Jannah, 2017, 216). Efektifitas dari metode debat ini tidak akan tercapai jika mahasiswa tidak mempunyai semangat dan motivasi untuk bisa menguasai bahasa Arab.

Hal ini terlihat dari hasil belajar mahasiwa Prodi PBA semester 3 IAI Muhammadiyah Sinjai yang kesulitan menyampaikan pendapat mereka saat sesi debat berlangsung. Mereka beralasan bahwa debat bahasa Arab itu sulit dan menakutkan. Perasaan seperti ini menyebabkan mahasiswa lupa pada kosa kata yang telah dipersiapkan, sehingga debat tidak bisa berlangsung maksimal. Oleh karena itu, untuk menumbuhkan semangat dan menghilangkan rasa takut 


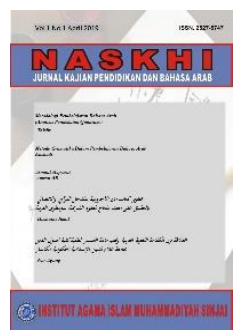

NASKHI

Jurnal Kajian Pendidikan dan Bahasa Arab

Volume 2, No. 1, 2020

ISSN (print) : 2527-5747

ISSN (online) : 2716-3369

Homepage : https://journal.iaimsinjai.ac.id/index.php/naskhi

tersebut diperlukan bantuan metode lain, seperti Suggestopedia yang bertujuan untuk mengembalikan dan meningkatkan motivasi belajar mahasiswa.

Metode suggestopedia juga pernah digunakan oleh Venkanna dalam meningkatkan pemahaman membaca bahasa inggris peserta didik. Dalam penelitian ini ia menemukan bahwa penggunaan musik selama proses pembelajaran menimbulkan rasa nyaman dan mengurangi kekhawatiran peserta didik selama proses pembelajaran berlangsung (Venkanna, 2015, 128).

Berdasarkan data dan fakta yang dijelaskan sebelumnya, maka peneliti berkeingan untuk meneliti efektifitas metode suggestopedia dalam meningkatkan kemampuan debat mahasiswa program studi pendidikan bahasa Arab di IAI Muhammadiyah Sinjai.

\section{B. METODE PENELITIAN}

\section{Desain Penelitian}

Penelitian peningkatan kemampuan debat bahasa Arab melalui metode suggestopedia ini menggunakan metode penelitian eksperimen dengan jenis Quasi Experimental Design. Jenis penelitian ini merupakan pengembangan dari penelitian eksperimen pre-experimental Design, di mana objek penelitian tidak bisa dibagi menjadi kelas kontrol dan kelas eksperimen secara random. Sedangkan bentuk desain penelitian yang digunakan adalah Time Series Design, yaitu dengan memberikan beberapa pretest untuk mengetahui kondisi objek penelitian yang sebenarnya (Sugiyono, 2015, 168).

\section{Teknik Pengumpulan Data}

Teknik atau metode yang digunakan untuk mengumpulkan data penelitian adalah:

a. Observasi, yaitu peneliti mengamati proses debat bahasa Arab yang dilakukan mahasiswa untuk mengumpulkan data penelitian awal. Observasi dilaksanakan dengan menggunakan lembar observasi yang terdiri dari indikator-indikator terkait materi dan proses pembelajaran yang sedang berlangsung.

b. Tes, yakni peneliti menyiapkan lembar tes yang terdiri dari beberapa pertanyaan atau tugas yang akan dilaksanakan oleh objek penelitian selama proses pretest dan postest. Selanjutnya data yang diperoleh dari hasil tes akan dianalisis dengan menggunakan uji $t$ untuk mengetahui seberapa besar pengaruh variabel $\mathrm{x}$ terhadap variabel $\mathrm{y}$.

c. Dokumentasi, yaitu peneliti mendokumentasikan kegiatan-kegiatan yang mendukung hasil penelitian, baik berupa gambar atau video penelitian.

\section{Sumber Data}

Data penelitian diperoleh dari analisis hasil observasi dan hasil tes baik pretest maupun postest yang diberikan kepada mahasiswa pendidikan bahasa Arab IAI Muhammadiyah Sinjai semester 3.

\section{Lokasi Penelitian}


Penelitian dilaksanakan di IAI Muhammadiyah Sinjai, Kabupaten Sinjai yang berada di Jl. Sultan Hasanuddin No 20, Balangnipa, Sinjai Utara.

\section{PEMBAHASAN}

Banyak cara yang bisa dilakukan untuk melatih kemampuan berbicara bahasa Arab, salah satunya adalah debat. Hanina Rahman (Rahman, tth, 2) menyebutkan bahwa debat merupakan sebuah pertentangan untuk mempertahankan argumentasi seseorang mengenai suatu hal yang diperkuat dengan teori dan bukti terkait. Debat bisa berlangsung di manapun, baik secara formal maupun non-formal. Banyak manfaat yang bisa diperoleh melalui proses debat ini (debat formal), di antaranya adalah melatih pembicara untuk menggunakan bahasa yang baik, jelas, dan tepat saat menyampaikan argumennya.

Dalam pembelajaran bahasa Arab, debat telah menjadi salah satu cara efektif untuk meningkatkan kemampuan bicara peserta didik atau yang lebih dikenal dengan Maharah Kalam. Maharah kalam sebagai satu dari empat kemahiran bahasa Arab telah menjelma menjadi tujuan pokok diajarkannya bahasa. Hal ini terlihat dari perubahan arah metode pembelajaran yang berkembang saat ini, mayoritas metodologi pembelajaran bahasa Arab yang digunakan tidak lagi berorientasi pada pemahaman bahasa sebagai sebuah ilmu, tetapi sudah bergeser dengan menjadikan bahasa sebagai alat berkomunikasi (Syamsiah, 2016, 66).

Pergeseran orientasilah yang ini menjadikan debat sebagai salah satu metode terbaik dalam melejitkan kemampuan bahasa Arab peserta didik. Burdah mengatakan bahwa debat dapat membantu pengembangan olah berfikir, memperluas wawasan, dan membangun sikap serta argumen yang kuat dan cerdas (Mahesi, 2017, 146). Untuk menyampaikan argumen yang berbobot, seorang debaters harus membekali diri dengan 4 kemampuan dasar, yaitu a) kemampuan berfikir berdasarkan fakta yang terjadi dilapangan dan logika yang benar, b) menguasai 4 keterampilan berbahasa (Maharah Istima', Kalam, Qira'ah, dan Kitabah), c) dapat menyampaikan pendapat dengan bahasa yang baik serta mampu menelaah dan menerima pendapat orang lain, d) kemampuan menghibur.

Kemampuan dasar tersebut bukanlah kemampuan yang bisa diperoleh secara instan dengan satu kali latihan, intensitas dan keinginan yang kuat dari peserta didik sangat mempengaruhi hasil yang akan diperoleh. Di samping itu keseimbangan antara kompetensi dan performa peserta didik juga akan mempengaruhi argumen yang disampaikan. Seorang penutur bahasa yang mengerti struktur bahasanya akan mampu mengkreasikan kalimat yang disampaikan dalam berbagai ungkapan (Mahesi, 2017, 147), namun kondisi inilah yang menjadi kendala utama keberhasilan seorang peserta didik dalam debat. Salah satu faktor yang mempengaruhi keberhasilan tersebut adalah 


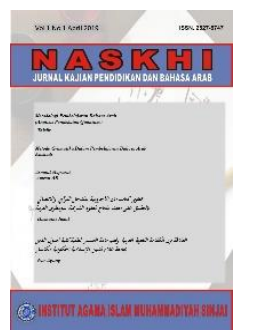

\section{NASKHI}

Jurnal Kajian Pendidikan dan Bahasa Arab

Volume 2, No. 1, 2020

ISSN (print) : 2527-5747

ISSN (online) : 2716-3369

Homepage : https://journal.iaimsinjai.ac.id/index.php/naskhi

situasi dan kondisi pembelajaran yang kondusif serta tema-tema debat yang sesuai dengan fakta yang terjadi saat itu.

Suggestopedia merupakan sebuah metode yang lahir dari aplikasi Suggesty sebuah aplikasi yang digunakan oleh Georgi Lozanof (seorang psikolog dan pendidik) untuk meningkatkan keberhasilan proses pembelaaran (Rohman, 2017, 233). Lozanof berpendapat bahwa metode Suggestopedia berusaha mempengaruhi pikiran dan perasaan peserta didik agar mereka dapat mencapai level yang lebih baik. Terdapat 3 asumsi dasar dalam penggunaan metode suggestopedia, yaitu:

1. Melibatkan fungsi sadar dan bawah sadar peserta didik dalam proses pembelajaran

2. Kurangnya suasana yang sesuai dengan kondisi peserta didik, serta kondisi pembelajaran yang kurang nyaman.

3. Sedikitnya potensi peserta didik yang dimanfaatkan oleh pengajar.

Ke tiga asumsi tersebut menjadi dasar Lozanof dalam menggunakan sugesti pada peserta didik, ia beranggapan bahwa dengan memanfaatkan fungsi bawah sadar peserta didik, rasa takut akan mengalami kegagalan akan semakin berkurang sehingga peserta didik menjadi termotivasi untuk meningkatkan kemampuan belajar mereka (Masri'ah, 2015, 26). Menurut Arsyad, metode suggestopedia memiliki 6 unsur pokok yang harus dipahami oleh pengajar, yaitu:

1. Authority, yaitu penguasaan pengajar terhadap materi yang disampaikan sehingga menjadikan peserta didik yakin bahwa pengajarnya mampu meningkatkan kemampuannya dalam pembelajaran.

2. Infantilisasi, yaitu menganggap peserta didik sebagai anak kecil yang dapat menerima otoritas pengajar. Hal ini diharapkan agar peserta didik dapat mengeluarkan kemampunya semaksimal mungkin tanpa harus terbebani dengan pembelajaran yang rasional dan menekan.

3. Dual-komunikasi, yaitu pengajar menggunakan sistem komunikasi verbal dan nonverbal berupa rangsangan semangan melalui kepribadian dan tingkah laku pengajar.

4. Intonasi, penggunaan nada suara yang tepat juga memberikan pengaruh yang baik pada peserta didik. Penyampaian materi dengan intonasi yang tepat akan membuat peserta didik semakin mudah dalam memahami materi yang diajarkan.

5. Irama, yaitu dengan mengatur kecepatan saat berbicara dan membaca sehingga menimbulkan ketertarikan peserta didik untuk mengikuti setiap perkataan pengajar.

6. Pseudo-pasif, yaitu dengan membawa peserta didik dalam kondisi yang benar-benar nyaman. Hal ini bisa dilakukan melalui penataan ruang kelas, belajar di tempat yang berbeda, penggunaan musik, serta metode pembelajaran yang beragam dan menyenangkan. 
Namun, sebagai sebuah metode, suggestodeia juga memiliki kelebihan dan kekurangan yang harus diperhatikan oleh pengajar terutama dalam proses pembelajaran bahasa Arab. Di antara kelebihan metode ini adalah (Rohman, 2017, 237):

1. Pembelajaran bahasa Arab menjadi sangat menyenangkan sehingga anggapan bahwa bahasa Arab itu sulit akan semakin berkurang.

2. Peserta didik mampu menghafalkan lebih banyak materi dalam waktu yang lebih cepat.

3. Konsentrasi peserta didik akan semakin meningkat karena didukung oleh suasana yang kondusif.

4. Imajinasi, wawasan, dan kemampuan peserta didik akan semakin berkembang karena adanya kepercayaan bahwa ia bisa menguasai pelajaran dengan lebih baik.

Banyaknya kelebihan dari metode ini tidak menjadika Suggestopedia sebagai metode terbaik tanpa cela, terdapat beberapa kekurangan yang harus diperhatikan oleh pengajar sebelum menggunakan metode ini, yaitu:

a. Membutuhkan biaya yang relatih mahal, karena harus mendesain ruangan belajar senyaman mungkin.

b. Peserta didik rentan terpengaruh dengan suasana yang ada, sehingga konsentrasi mereka akan teralihkan.

c. Keterampilan yang dikuasai akan sangat dipengarui oleh suasana yang diciptakan.

Metode Suggestopedia sangat bergantung pada kemampuan dan kreatifitas pengajar dalam menciptakan situasi belajar yang kondusif, kekeliruan saat mengkreasikan suasana belajar akan sangat berpengaruh pada tujuan dan hasil belajar yang ingin dicapai. Oleh karena itu, pertimbangan dan persiapan yang matang sangat diperlukan dalam penerapan metode ini.

\section{Metode Suggestopedia dan Debat Bahasa Arab}

Peserta didik merupakan individu unik yang memiliki karakteristik dan kecendrungan yang berbeda antara satu dengan lainnya. Dalam satu ruang belajar, terdapat berbagai karakter yang membutuhkan perhatian khusus dari pendidik saat menyampaikan materi pelajaran. Perhatian ini sangat berpengaruh pada tingkat ketercapaian tujuan pembelajarn, seorang pendidik yang tidak memahami karakteristik peserta didiknya secara saksama akan mengalami kesulitan dalam menyampaikan materi ajar dengan berbagai metode yang ada.

Pemahaman terhadap karakter peserta didik ini termasuk dalam problematika pembelajaran bahasa Arab yang bersifat non-linguistik, akan tetapi buka problematika yang bersifat eksternal. George Lozanov seperti 


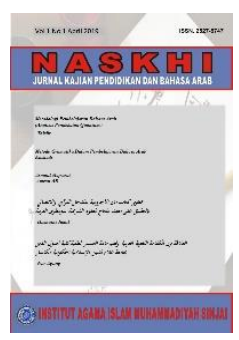

\section{NASKHI}

\section{Jurnal Kajian Pendidikan dan Bahasa Arab}

Volume 2, No. 1, 2020

ISSN (print) : 2527-5747

ISSN (online) : 2716-3369

Homepage : https://journal.iaimsinjai.ac.id/index.php/naskhi

yang dijelaskan sebelumnya menyebutkan bahwa aspek psikologi memberikan kontribusi besar dalam tingkat keberhasilan suatu pembelajaran.

Perhatian terhadap aspek psikologi ini dituangkan para pakar pendidikan denga melahirkan beberapa metode pembelajaran yang dapat digunakan pendidik untuk mengatasi berbagai problematika pendidikan, seperti The Silent Way, Suggestopedia, The Natural Approach, Community Language Learning, dan sebagainya.

Metode Suggestopedia hadir dengan berdasarkan pada asumsi bahwa peserta didik harus melibatkan fungsi sadar dan di bawah sadarnya dalam proses pembelajaran, suasana yang kurang serasi dan santai akan menurunkan hasil belajar peserta didik, serta kurang dimanfaatkannya potensi dasar yang dimiliki oleh peserta didik.

Dala proses pembelajaran bahasa Arab terutama dalam meningkatkan kemampuan berbicara peserta didik, suasana yang santai dan ruang untuk mengembangkan kemampuan mereka sangatlah diperlukan, oleh karena itu kehadiran Metode Suggestopedia dalam dunia pendidikan seolah-olah memberikan angin segar bagi para penggiat pembelajaran Bahasa Arab. Di Perguruan Tinggi contohnya, pembelajaran bahasa Arab yang sudah masuk pada taraf mahir mewajibkan mahasiswanya untuk menguasai bahasa Arab secara menyeluruh. Salah satu aspek yang harus dikuasai mahasiswa pendidikan bahasa Arab adalah kemampuan berbicara kritis (debat) dengan menggunakan bahasa Arab.

Kemampuan debat bahasa Arab ini dapat ditingkatkan dengan menggunakan metode yang mampu memberikan kenyamanan kepada mahasiswa untuk berpikir secara kritis dan mengungkapkan gagasan mereka dengan bahasa Arab yang baik. Metode dengan manfaat tersebut dapat ditemukan dalam penggunaan Metode Suggestopedia.

Berdasarkan perbandingan hasil pretest dan postest dari kelas eksperimen diketahui hasil sebagai berikut

\section{Paired Samples Statistics}

\begin{tabular}{rrr|r|r|r} 
& & Mean & N & Std. Deviation & Std. Error Mean \\
\hline Pair 1 & Pretest & 60,41 & 17 & 6,501 & 1,577 \\
\cline { 2 - 6 } & Postest & 81,47 & 17 & 6,063 & 1,471 \\
\hline
\end{tabular}

\section{Paired Samples Correlations}




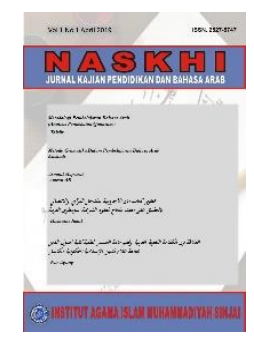

\begin{tabular}{llr|r|r} 
& & & & \\
& $N$ & Correlation & \multicolumn{1}{l}{ Sig. } \\
\hline Pair 1 & Pretest \& Postest & 17 &, 340 &, 181 \\
\hline
\end{tabular}

\begin{tabular}{|c|c|c|c|c|c|c|c|c|c|}
\hline \multicolumn{10}{|c|}{ Paired Samples Test } \\
\hline & \multicolumn{6}{|c|}{ Paired Differences } & \multirow[b]{3}{*}{$\mathrm{t}$} & \multirow[b]{3}{*}{$\mathrm{df}$} & \multirow{3}{*}{$\begin{array}{l}\text { Sig. (2- } \\
\text { tailed) }\end{array}$} \\
\hline & & \multirow[b]{2}{*}{ Mean } & \multirow{2}{*}{$\begin{array}{c}\text { Std. } \\
\text { Deviation }\end{array}$} & \multirow{2}{*}{$\begin{array}{l}\text { Std. } \\
\text { Error } \\
\text { Mean } \\
\end{array}$} & \multicolumn{2}{|c|}{$\begin{array}{l}95 \% \text { Confidence } \\
\text { Interval of the } \\
\text { Difference }\end{array}$} & & & \\
\hline & & & & & Lower & Upper & & & \\
\hline Pair 1 & $\begin{array}{l}\text { Pretest - } \\
\text { Postest }\end{array}$ & $-21,059$ & 7,224 & 1,752 & $-24,773$ & $-17,345$ & $\begin{array}{r}- \\
12,020\end{array}$ & 16 &, 000 \\
\hline
\end{tabular}

Berdasarkan tabel di atas dapat diketahui bahwa nilai $-\mathrm{t}$ hitung = 12,020 , sedangkan $t$ tabel dengan jumlah responden 17 orang adalah 17$1=16=-2,120$ berdasarkan standar signifikansi $0,05 / 2=0,025$. Maka dapat diperoleh hasil bahwa $-\mathrm{t}$ hitung $<\mathrm{t}$ tabel dengan nilai $-12,020<-2,120$, oleh karena itu Ho di tolak, jadi kemampuan debat bahasa Arab mahasiswa pendidikan Bahasa Arab mengalami peningkatan yang signifikan dengan penggunaan Metode Suggestopedia.

\section{PENUTUP}

Bahasa Arab sebagai salah satu bahasa internasional yang semakin berkembang membutuhkan pembaruan dalam berbagai aspek pembelajarannya, salah satunya adalah dari aspek metode pembelajaran yang digunakan. Kehadiran metode Suggestopedia dalam dunia pendidikan, dapat dimanfaatkan semaksimal mungkin untuk meningkatkan kemampuan mahasiswa dalam debat berbahasa Arab. Dengan metode ini, proses debat dapat berlangsung dengan nyaman dan santai sehingga mahasiswa mampu menyampaikan gagasan-gagasan mereka terkait tema yang dibahas dengan bahasa yang baik tanpa ada tekanan formalitas.

Berdasarkan hasil penelitian ini dapat disimpulkan bahwa penggunaan metode suggestopedia dalam meningkatkan kemampuan debat bahasa Arab mahasiswa memberikan hasil yang signifikan sehingga mahasiswa bahasa Arab tidak hanya paham teori berbahasa tapi juga mampu menggunakan bahasa dengan baik sesuai dengan kaidah yang berlaku.

\section{E. DAFTAR PUSTAKA}




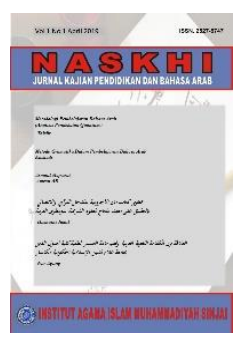

\section{NASKHI}

\section{Jurnal Kajian Pendidikan dan Bahasa Arab}

Volume 2, No. 1, 2020

ISSN (print) : 2527-5747

ISSN (online) : 2716-3369

Homepage : https://journal.iaimsinjai.ac.id/index.php/naskhi

Cahyono. 2011. Suggestopedia: Pendekatan Pembelajaran Bahasa Kedua yang Bersifat Humanistik. Journal Pendidikan Vo. 17, No. 2.

Hafidah. 2012. Metode Pembelajaran Bahasa Arab Komunikatif (Metode Suggestopedia dan Metode Community Language Learning). Forum Tarbiyah, Vol 1, No. 2.

Jannah, Fithrotul. 2017. Pembelajaran Debat Bahasa Arab melalui Model International Universities Arabic Debating Championship $(I U A D C)$, Qatar. Malang: Prosiding Konferensi Nasional Bahasa Arab III.

Madkuk, 'Ali Ahmad Madkur. 1984. Tadris Funuun Al Lughah Al 'Arabiyah. Maktabah Al Fallah

Maulana, M. Khakim. Pemanfaatan Metode Suggestologi Sebagai Revitalisasi Semangat Belajar Bahasa Arab dalam Maharah Kalam di Era Milenial.

https://s3.amazonaws.com/academia.edu.documents/Pemanfaatan Metode_Suggestology_Sebagai.

Masnun. 2018. Teori Linguistik dan Psikologi dalam Pengajaran Bahasa Arab di Lembaga Pendidikan Islam. Jurnal Pendidikan Islam. Vol. 08, No. 01 .

Masri'ah. 2015. Penggunaan Metode Silent Way dan Suggestopedia dalam Pembelajaran Bahasa Arab. El-Ibtikar Vol. 04, No. 02.

Rahman, Hanina Emita. 2018 Pengembangan Media "Kolibers" (Kotak Liku Bersuara) pada Materi Debat Menggunakan Metode Debat Aktif. Bapala, Vol.5 No 2.

Retnani, Rahna Mahesi. 2017. Disekuilibrium Kompetensi dan Performansi Mahasiswa BSA dalam Debat Bahasa Arab berdasarkan Perspektif Noam Chomsky. Prosiding Seminar Nasional Bahasa Arab Mahasiswa I.

Rohman, Fathur. 2015. Metodologi Pembelajaran Bahasa Arab. Malang: Madani

Sugiyono. 2015. Cara Mudah Menyusun Skripsi, Tesis, dan Disertasi. Bandung: Alfabeta

Syamsiah, 2016. Dailatus. Arah Baru Belajar Bahasa Arab di Perguruan Tinggi. Jurnal Komunikasi dan Pendidikan Islam, Vol. 6, No.2.

Venkanna, Kuncham. 2015. Use of Suggestopedia as an Innovative Strategy for Promoting Effective Reading Comprehension Abilities in English at the ESL level. IJELLH: International Journal of English Language, Literature and Humanities, Vol III Issue VIII. 
Volume 2, No. 1, 2020

ISSN (print) : 2527-5747

ISSN (online) : 2716-3369

Homepage : https://journal.iaimsinjai.ac.id/index.php/naskhi 